\title{
The economic costs of Hurricane Harvey attributable to climate change
}

\author{
David J. Frame ${ }^{1} \cdot$ Michael F. Wehner ${ }^{2} \cdot$ Ilan Noy $^{3} \cdot$ Suzanne M. Rosier ${ }^{4}$
}

Received: 10 April 2019 /Accepted: 9 March 2020 / Published online: 8 April 2020

(C) The Author(s) 2020

\begin{abstract}
Hurricane Harvey is one of the costliest tropical cyclones in history. In this paper, we use a probabilistic event attribution framework to estimate the costs associated with Hurricane Harvey that are attributable to anthropogenic influence on the climate system. Results indicate that the "fraction of attributable risk" for the rainfall from Harvey was likely about at least a third with a preferable/best estimate of three quarters. With an average estimate of damages from Harvey assessed at about US\$90bn, applying this fraction gives a best estimate of US\$67bn, with a likely lower bound of at least US\$30bn, of these damages that are attributable to the human influence on climate. This "bottom-up" event-based estimate of climate change damages contrasts sharply with the more "top-down" approach using integrated assessment models (IAMs) or global macroeconometric estimates: one IAM estimates annual climate change damages in the USA to be in the region of US\$21.3bn. While the two approaches are not easily comparable, it is noteworthy that our "bottom-up" results estimate that one single extreme weather event contributes more to climate change damages in the USA than an entire year by the "top-down" method. Given that the "top-down" approach, at best, parameterizes but does not resolve the effects of extreme weather events, our findings suggest that the "bottom-up" approach is a useful avenue to pursue in future attempts to refine estimates of climate change damages.
\end{abstract}

Keywords Climate change · Economic cost · Event Attribution · Hurricane Harvey

David J. Frame

david.frame@vuw.ac.nz

1 New Zealand Climate Change Research Institute, Victoria University of Wellington, Wellington 6012, New Zealand

2 Computational Research Division, Lawrence Berkeley National Laboratory, Berkeley, CA, USA

3 Department of Economics, Victoria University of Wellington, Wellington 6012, New Zealand

4 National Institute of Water and Atmospheric Research, Wellington 6021, New Zealand 


\section{Introduction}

The use of information from climate change attribution studies to quantify damages associated with climate change was proposed about 15 years ago (Allen, 2003), and recent work has suggested the approach can be valuable as one component within a wider systematic assessment of climate change costs (Millar et al., 2018, Frame et al., 2018). This approach can also provide a valuable measurement tool for quantification that can be used in discussions regarding compensation and loss and damage. Here we present an application of this approach to the costs associated with Hurricane Harvey, one of the most expensive cyclones in history. We compare the damages implied by this "bottom-up" attribution-based approach with damages implied by a commonly used integrated assessment model, DICE, in a more "topdown" type of approach (Nordhaus, 1993, Nordhaus and Boyer, 1999).

Damages from an extreme weather event occur during and immediately after the hazard event. These damages are usually measured in physical units (e.g., units of housing, square meters of housing, kilometers of roads or electricity lines, number of bridges, etc.) and describe the partial or total destruction of physical assets, the disruption of basic utility services, and damages to sources of livelihood in the affected area (e.g., crops). Disaster damage or direct economic loss is the monetary value of destruction of physical assets located in the affected area. Examples of physical assets that are the basis for calculating direct economic damage include homes, schools, hospitals, commercial and governmental buildings, transport, energy, telecommunications infrastructures, and other infrastructures; business assets and industrial plants; and production outputs such as crops, livestock, and manufacturing inventories. In principle, direct economic damage, a "stock" measure, may also encompass environmental assets and cultural heritage, inasmuch as they provide economic services (e.g., via tourism), but these are very difficult to quantify and hence rarely quantified. Most direct economic damages are tangible and relatively easy to measure.

Direct economic damages can cause subsequent indirect economic loss which includes microeconomic impacts (e.g., firms' revenue declines owing to business interruption or loss of household wage income), meso-economic impacts (e.g., revenue declines owing to impacts on natural assets, interruptions to supply chains, or temporary unemployment), and macroeconomic impacts (e.g., declines in GDP, increases in government debt, price and exchange rate changes, movements in stock market prices). Indirect losses can occur within or outside of the area directly exposed to the hazard and can often be experienced with a significant time lag. In some cases, economic losses are still identifiable decades after the event has happened. As a result, they may be intangible or very difficult to measure.

From 17 August to 5 September 2017, Hurricane Harvey made its way across the Caribbean Sea and onto mainland North America. It subsequently made landfall in Texas as a Category 4 hurricane, moved slightly offshore, weakened to a tropical storm, and stalled for several days while dumping copious amounts of rain in the greater Houston area. Much of the damages from Harvey were a result of widespread inland flooding, mostly of a pluvial nature (Wing et al., 2019, Abbott and Al, 2018, Lindner and Fitzgerald, 2018). Hurricane Harvey occurred in 2017, so any comprehensive quantification of its associated indirect economic losses is still impossible: reliable economic data are only available with a significant time lag, and the indirect economic losses might still be observable in economic data even 3-4 years after the event (in some extreme cases, they might even be evident decades after(Noy and 
duPont, 2018)). Here we therefore focus on the direct economic damages, as these were counted by four different organizations (a US Federal Government agency, an international NGO, and two large European Reinsurance companies).

The estimate of the costs we provide is not a substitute, or a direct comparison, with cost estimates derived either from macroeconomic analyses or from IAMs. Rather, our estimate should be seen as a new strand of evidence which, when combined with similar estimates of other economic losses (and gains) from climate change, could provide a useful line of evidence which could then inform macroeconomic and IAM-centered approaches.

\section{Results}

To develop a bottom-up assessment of the costs of Hurricane Harvey (or potentially any other event), we require assessment of the anthropogenic contribution to the event, as well as an accompanying estimate of the costs of the event. Probabilistic event attribution provides the climate science input, and economic analyses provide the costs of the weather event.

\section{Probabilistic event attribution}

Following a flood in 2003 at his Oxford home, Allen(Allen, 2003) proposed that the influence of anthropogenic climate change on individual extreme weather events could be quantified with the use of climate models. Such investigations into the causal factors of extreme weather have become known as "extreme event attribution." Subsequent developments have expanded this field to include analyses of numerous types of extreme weather (Peterson et al., 2012, Peterson et al., 2013, Herring et al., 2015, Herring et al., 2016, Herring et al., 2018). Attribution of the influence of anthropogenic climate change on individual hurricanes began in earnest with Harvey (Emanuel, 2017, Risser and Wehner, 2017) (Oldenborgh et al., 2017, Trenberth et al., 2018, Wang et al., 2018). Event attribution analyses often treat causality with two different but equivalent approaches. In a mechanistic approach, termed the "Boulder school"(Easterling et al., 2016), attributable changes in event magnitude at a fixed estimate of the actual event's probability are estimated. However, to calculate the "fraction of attributable risk" (FAR) (Eq. 1), the probabilistic or "Oxford school" approach of estimating attributable changes in event probability at a fixed estimate of the actual event's magnitude is more appropriate. We do note, however, that these different framing approaches are scientifically consistent with each other (Otto et al., 2012) and that many sophisticated event attribution studies present results from both methodologies.

In estimating the risk of events attributable to anthropogenic climate change, we follow the IPCC Working Group I definition(Bindoff et al., 2013) of the fraction of attributable risk as follows: "Fraction Attributable Risk, defined as

$$
F A R=1-\frac{P_{\mathrm{o}}}{P_{1}}
$$

$P_{0}$ being the estimated probability of an event occurring in the absence of human influence on climate, and $P_{l}$ the corresponding probability in a world in which human influence is included. 
FAR is thus the fraction of the risk that is attributable to human influence (or, potentially, any other external driver of climate change) and does not require knowledge of absolute values of $P_{0}$ and $P_{1}$, only their ratio." The ratio of these probabilities, $\left(\mathrm{P}_{1} / \mathrm{P}_{0}\right)$, is often termed the "risk ratio" (RR) under the assumption that exposure may be considered the same in both the actual and counterfactual worlds. FARs are dimensionless likelihood ratios: the new likelihood of an event above an event threshold (magnitude or frequency) compared with the old likelihood of encountering an event above that same threshold. Other researchers have also pointed to the potential for RRs (and FARs) to inform calculations like the one argued for here: "[risk] ratio can be interpreted as a lower bound to relative changes in the expected losses due to the extremes provided that the consequences of extreme events of a fixed intensity do not decrease with warming, consistent with expectations. This simple concept may therefore provide a powerful tool for high-level cost-benefit analysis.'(Kharin et al., 2018).

Two analyses of Hurricane Harvey, coming from independent groups using very different methodologies, present probabilistic attribution statements about the storm's rainfall. A recent study (Oldenborgh et al., 2017) analyzed extreme precipitation changes in the US Gulf Coast region from three different $\sim 25 \mathrm{~km}$ climate models. Using the IPCC calibrated language, they stated that the probability of the observed amount of precipitation was increased by a factor of 3 by anthropogenic climate change with a very likely range of this factor of 1.5 to 5 . A different analysis (Risser and Wehner, 2017) used a non-stationary extreme value statistical model to analyze observed 7-day precipitation totals from weather stations in two Texas regions, one contained within the other. For the smaller region, with its larger precipitation amount (> $700 \mathrm{~mm}$ ), their best estimate-derived from a maximum likelihood approach-is that changes in atmospheric $\mathrm{CO} 2$ since 1950 increased the storm total precipitation by a factor of 9.6 with a likely lower bound of 3.5. For the larger region (7-day precipitation $>480 \mathrm{~mm}$ ), their best estimate is that precipitation was increased by a factor of 5 with a likely lower bound of 1.4. The lower bound on the RR in (Risser and Wehner, 2017) is insensitive to uncertainties in both observed rainfall and in estimates of its probability, consistent with a previous analysis (Jeon et al., 2016). These RRs, and their corresponding FAR values, are shown in Table 1.

These two attribution studies are completely independent as they both use different methods and observational datasets. The climate model-based statement is a causal statement interpreted in the manner of (Pearl, 2009) in which an intervention is made in the experiment by removing the anthropogenic forcings in a counterfactual simulation. The statistical modelbased statement does not use climate models and is a different class of causal inference interpreted in the manner of Grainger (Ebert-Uphoff and Deng, 2012). Both classes of causal inference statements have caveats. Grainger statements may lack the influence of "hidden"

Table 1 Estimates of RRs and FAR from studies of Hurricane Harvey (Risser and Wehner, 2017, Oldenborgh et al., 2017)

\begin{tabular}{|c|c|c|c|c|c|c|}
\hline & \multicolumn{2}{|c|}{ Lower estimate } & \multicolumn{2}{|c|}{ Best estimate } & \multicolumn{2}{|c|}{ Upper estimate } \\
\hline & $\mathrm{RR}$ & FAR & RR & FAR & RR & FAR \\
\hline Oldenborgh et al., 2017 (climate model) & 1.5 & 0.33 & 3 & 0.67 & 5 & 0.8 \\
\hline $\begin{array}{l}\text { Risser and Wehner, } 2017 \text { (statistical model) } \\
\text { large region }\end{array}$ & 1.4 & 0.29 & 5 & 0.8 & - & \\
\hline $\begin{array}{l}\text { Risser and Wehner, 2017(statistical model) } \\
\text { small region }\end{array}$ & 3.5 & 0.71 & 9.6 & 0.9 & & \\
\hline Average of VO and RW (large region) & 1.45 & 0.31 & 4 & 0.75 & & \\
\hline
\end{tabular}


covariates, while Pearl statements may reflect the errors of the climate models. As the RRs for the large region compare well across studies despite the very different tools and approaches to causal inference (Risser and Wehner, 2017, Oldenborgh et al., 2017), confidence in a sizeable human influence on precipitation during Harvey is increased. Hence, we simply average these two RRs of the large region (last row of Table 1) to estimate the lower bound and best estimate of attributable costs of Harvey due to climate change. For the upper bound, we simply use the sole available estimate which is from the climate model-based approach.

\section{Estimated economic costs}

The estimated economic damage costs that we use in our calculations originate from several sources. The National Oceanic and Atmospheric Administration (NOAA) produces estimates of the costs associated with US weather events. For Hurricane Harvey, their current estimate of US\$125 billion is from an updated list of hurricane costs in 2017 (Information, 2018). Generally, this should be construed as a preliminary estimate and is conservative as the methodology used typically underestimates losses by 10-15\% (Smith and Katz, 2013).

The world's two largest reinsurance companies globally, Munich Re and Swiss Re, produce their own estimates of the total value of damages associated with natural disasters. These databases-NatCat and Sigma, respectively-are then used internally for their business. They also publish estimates for the most extreme events each year, always in January of the following year. For Hurricane Harvey, both sources cite a figure of US\$85 billion, out of which they estimate that US\$30 billion was insured. While these should be independent estimates, they do not appear to be, so we treat them as a single estimate.

Last, an international NGO, the Centre for Research on the Epidemiology of Disasters (CRED), produces its own publicly available database of disaster damages: EMDAT (www. emdat.be). It collects data from "various sources, including UN agencies, non-governmental organisations, insurance companies, research institutes and press agencies." EMDAT includes a somewhat higher figure for the damages from Harvey of US\$95 billion. The most authoritative source for disaster data might be the UN-supported DesInventar (www.desinventar.net) that is now the official data collection mechanism to support the Sendai Framework for Disaster Risk Reduction (an international agreement signed by almost all countries and endorsed by the United Nations' General Assembly in 2015). Unfortunately for our purposes, the USA has not yet begun to report its data to DesInventar.

Given the discussion of the available data above, the average estimate for the direct economic cost associated with damages to physical assets from Hurricane Harvey is US $\$ 90$ billion (average of EMDAT and the Munich Re/Swiss Re estimates).

In principle, the analysis tying FARs to damages should relate the amount of damage incurred in each asset class (horizontal infrastructure by type, commercial and industrial properties, each type of residential buildings, etc.) to its damage function, and by using the two points in the damage function (with and without anthropogenic climate change), calculate how much of the measured damages, for each asset class, is attributable to anthropogenic influence. Unfortunately, we do not have this information separated by asset class. Fortunately, however, the damage function for the most asset classes (especially the most significant ones) are about linear in flood depths of up to 2-3 m, and flood depths in Houston were generally significantly lower than that (Huizinga et al., 2017). Nordhaus (Nordhaus, 2010), using a more aggregated data, describes a very convex non-linear damage function in his investigation of 
hurricane damage costs and wind speed; however, the asset damage for Hurricane Harvey, and for many other tropical cyclones, is mostly associated with water, and not wind (Yonson et al., 2018), justifying the use of a linear damage function. Based on the methods described above, we assess the direct economic costs of Hurricane Harvey that are attributable to anthropogenic influences on the climate to likely be in the range of US\$30bn to US\$72bn, with a best estimate of US\$67bn.

This estimate quantifies only the direct damage that can be easily monetized. It does not include mortality, morbidity, and temporary and permanent dislocations that are typically associated with hurricanes such as Harvey. In order to include these in the estimates, one could potentially calculate the attributable mortality using a similar method and measure it with the monetary value of life (VSL, the "value of a statistical life" (Viscusi and Aldy, 2003)). VSL measures, however, are difficult for any cross-country comparisons, and UNISDR (2015) (UNISDR, 2015) and Noy(Noy, 2016) suggest a different aggregate measure, of life-years lost, that overcomes some of these difficulties. It aims to account not only for the total direct damage estimates described in Table 2 but also for mortality and other affected population impacts. All are aggregated into a single measure, but without using VSL.

This life-years index consists of the following: Lifeyears ${ }_{i}=L_{i}\left(M, A^{\text {death }}, A^{\exp }\right)+I_{i}(N)+$ $D A M_{i}(Y, I N C) . L(\cdot)$ is the number of life-years lost due to mortality, calculated as the difference between the age at death $\left(A^{\text {death }}\right)$ and life expectancy $\left(A^{\exp }\right) .{ }^{1}$ Using the information about the deaths from Harvey, we use an average age at death of 49 and life expectancy of 92 (following the WHO conventional practice when calculating disability-adjusted life years). $I(N)$ is the cost function associated with the people who were injured or otherwise affected by the disaster (this information is only available from EMDAT; see Table 2). Since we do not have information about how each individual was affected, we assume that affected people were experiencing what the World Health Organization calls "generic uncomplicated disease: anxiety about diagnosis." This generic diagnosis implies that the coefficient used to convert the number of people affected $(N)$ to life-years lost is 0.054 (i.e., $I(N)=0.054 \mathrm{~N}$ ).

The last component of the life-years index, $\operatorname{DAM}(Y, I N C)$, attempts to account for the number of human life-years lost as a result of the damage to capital assets and infrastructure - including residential and commercial buildings, public buildings, and other types of infrastructure such as roads, water, sewage, electricity, and communication systems, all measured in monetary units $(Y)$. This measure (DAM) aims to measure the opportunity cost of spending resources (especially human effort) on the reconstruction of these destroyed assets. We use income per capita (INC) as an indicator of the cost of human effort in calculating this loss and assume that a quarter of a life-year is spent on generating income. This implies that $D A M(Y, I N C)=0.25\left(\frac{Y}{I N C}\right)$. Overall, we find that about 476,000 life-years were lost as a direct damage of Hurricane Harvey with almost $80 \%$ of the loss associated with the monetized damages to physical assets. For life-years, we therefore estimate that it is likely that at least 148,000 life-years, with a best estimate of 357,000 life-years, lost were directly attributable to anthropogenic climate change. This figure incorporates impacts (mortality and disruption to life) that are not accounted for by the direct damage figures (the US\$90 billion that was previously discussed). As such, it shows that, at least by this metric, the $\$ 90$ billion dollar is underestimating the impact of Harvey's rainfall. A fuller accounting of direct damages that

\footnotetext{
${ }^{1}$ Using the information about the deaths from Harvey, we use an estimated average age at death of 49 . This was calculated using the distribution of age at death and gender as described in Jonkman et al., 2018. Brief communication: Loss of life due to Hurricane Harvey. Nat. Hazards Earth Syst. Sci., 18, 1073-1078.
} 
Table 2 Estimates of the direct and insured damages, number of people affected by and number of deaths arising from Hurricane Harvey

\begin{tabular}{lllll}
\hline Datasets & $\begin{array}{l}\text { Direct damage } \\
\text { (In 2017 US\$ billion) }\end{array}$ & $\begin{array}{l}\text { Insured damage } \\
\text { (In 2017 US\$ billion) }\end{array}$ & $\begin{array}{l}\text { Number of people affected } \\
\text { (in thousands) }\end{array}$ & Mortality \\
\hline NOAA & 125 & & & 68 \\
EMDAT & 95 & 30 & 582 & 88 \\
Munich Re & 85 & 30 & & 88 \\
Swiss Re & 85 & 30 & & 88 \\
\hline
\end{tabular}

includes also mortality and morbidity will increase this figure by $25 \%$ due to the mortality and morbidity associated with the event and potentially more because of damage to non-monetized assets (such as environment amenities).

\section{Comparisons to top-down estimates of the costs of climate change}

There are two main ways of obtaining top-down global estimates of the costs of climate change. The first relies on integrated assessment models (IAMs) that incorporate a simplified model of the macroeconomy together with a climate model and a hypothesized link between the two (typically based only on the impact of temperature on economic production). The three most notable IAMs are DICE, FUND, and PAGE. The other alternative is to rely on macroeconometric estimates that are based on the past, typically annual, national level data on production (GDP) and average temperature (e.g., (Burke et al., 2015)).

For example, the DICE model (Nordhaus and Boyer, 1999) estimates a climate change damage function based on the equation $D=\varphi \Delta T^{2}$, where $D$ is climate change-induced damages to the global economy in percent and $\Delta T$ is the change in global mean surface temperature (we assume $\Delta T_{2019}=1.0 \mathrm{~K}$ ). The coefficient $\varphi$ was calculated based on the previous estimates from other studies and equals 0.00267. (The 2016 update has an even lower value for $\varphi$.) If the global GDP for 2017 equals US\$79,845bn (from the World Bank's World Development Indicators), then the DICE equation, which calculates the cost as a percent of global GDP, suggests that the annual global climate change damages ought to be of the order of US\$213bn. Furthermore, a recent study of the domestic social cost of carbon in the USA estimated that roughly $10 \%$ of global damages occur within the USA (Office of Air Quality Planning and Standards, 2017) (EPA document, p162), implying that the total US damages from climate change should currently be around US\$21.3bn. This DICE-based estimate is less than our likely lower bound of US\$30bn for the direct climate changeattributable costs of rainfall from Harvey alone, and it is much lower than our main estimate of US\$67bn. The study (Office of Air Quality Planning and Standards, 2017) of the domestic social cost of carbon also used two other IAMs, PAGE and FUND. The central estimates of climate damages of both of these models are lower than that of DICE, so the comparison we make between our bottom-up estimate of attributable direct costs compared with the estimated damages apply just as much to these other models, too.

The estimates for current climate change impacts for the USA from a recent macroeconometric study (Burke et al., 2015) are similarly low. While the paper does not provide country-specific estimates, they describe a general non-linear effect of temperature on the output. They find that the output peaks at about $13{ }^{\circ} \mathrm{C}$ and declines thereafter. Since the US annual average temperature is still below that threshold, and was below it in 2017, their 
modeling estimates a current benign impact of climate change on the US economy. More recent unpublished work, using regional rather than national-level data, suggests current adverse impacts for the USA, but as yet quite small (Kalkuhl and Wenz, 2018). It is noteworthy, however, to point out that their macroeconometric estimates ultimately predict future losses, for the year 2100, that are much larger than the future losses predicted by the leading IAMs.

In any case, our "bottom-up" estimate of the anthropogenic component of this very damaging single event, the precipitation associated with Hurricane Harvey, is far in excess of the "top-down" macro estimate arrived at through the application of a simple damage function in integrated assessment models (IAMs) such as DICE or those obtained from macroeconometric estimates of historical data. That a single event can do direct damages in excess of three times the modeled value of all annual loss in the USA as predicted by DICE is striking. There may be several elements driving this result.

The best estimate of FAR (0.75) implies that an event similar to the rainfall associated with Harvey has become far more likely than an event of the same magnitude would have been in the preindustrial world. This kind of event is still very rare, so it may be possible that the average annual losses for the USA are closer to the DICE-based estimate than to the figure obtained in this study for one rare event. However, Hurricane Harvey was the only one event in 2017. The inclusion of the two other destructive hurricanes that made landfall (Irma and Maria; together, they caused more damage and took far more lives than Harvey) and the numerous other weather events that impacted the USA that year raise the NOAA estimate of US weather-related losses to over $\$ 300 \mathrm{Bn}$, a new record. EMDAT lists 24 weather-related disasters in 2017 in the USA, and each of them may be associated with a FAR >0, but it is important to note that climate change could have also made some catastrophic events less likely $(\mathrm{FAR}<0)$. Ultimately, to obtain a full bottom-up estimate of the impact of climate change, one that could be directly comparable with the top-down estimates from the IAMs or the macroeconometric estimates, one would have to obtain economic damage assessments of all types of possible extreme weather events.

Damages functions are of course very difficult to estimate-they have been called "a notoriously weak link in the economics of climate change" (Weitzman, 2012) on the basis of deep structural uncertainty in their underlying functional form. It is quite likely that the simple approach used to characterize damages in IAMs ignores important dimensions of climate change. For instance, the functional form of climate damages is usually taken to be some function of the temperature anomalies, as is the case in the DICE example above, while losses from Harvey had very little to do with the direct effect of temperature anomalies and more to do with increased available moisture and storm structural changes leading to super Clausius-Clapeyron scaling of extreme precipitation (Patricola and Wehner, 2018). In other words, some aspects of climate change that are highly relevant to economic losses from climate change may be changing faster, and with a different pattern, than IAM-based damage functions suggest or can account for.

In summary, this study reveals that a bottom-up approach to a single event based on the FAR method and a top-down model-based approach such as DICE, PAGE, or FUND do not produce consistent estimates of the cost of climate change. There are important senses in which the two are not directly comparable: the IAM and macro-based approaches are aggregative, and in this study, we have focused on a single event. The FAR-based estimate is not a substitute or alternative for the total cost estimates. Nevertheless, the scale of the FAR-based estimate is striking and indicates that considerably more research is needed to reconcile top- 
down and bottom-up estimates of the costs of climate change. This need to quantify the costs has a particular urgency in light of recent decisions taken at the UN Climate Negotiations in Katowice, which opened a path for Parties to "provide, as appropriate, information related to enhancing understanding, action and support, on a cooperative and facilitative basis, to avert, minimize and address loss and damage associated with climate change impacts, taking into account projected changes in climate-related risks, vulnerabilities, adaptive capacities and exposure, including, as appropriate, on: (a) Observed and potential climate change impacts, including those related to extreme weather events and slow onset events, drawing upon the best available science."(UNFCCC, 2018). We have shown that there is a gap between the tools we use to inform climate policy and the actual damages being done by climate change. Research to understand the nature of this gap, and then to close it, is urgently needed.

Acknowledgments We thank Luke Harrington, Fredi Otto and Daithi Stone for valuable discussions. Thanks to Myles Allen and Hinksey Stream for their seminal contributions to discussions of event attribution and economic losses.

Author contributions DJF and MFW conceived the study. MFW led the attribution component and IN led the economic dimensions. All authors contributed to extensive discussions and jointly wrote the paper.

Funding information DJF, IN and SMR thank the New Zealand Treasury, the Deep South Challenge and especially the Endeavour Fund Whakahura program for support. Wehner was supported by the University of California's Office of the President for this study. The Lawrence Berkeley National Laboratory is operated for the Department of Energy Office of Science under contract number DE-AC02-05CH11231. This document was prepared as an account of work sponsored by the US Government. While this document is believed to contain correct information, neither the US Government nor any agency thereof, nor the Regents of the University of California, nor any of their employees, makes any warranty, express or implied, or assumes any legal responsibility for the accuracy, completeness, or usefulness of any information, apparatus, product, or process disclosed, or represents that its use would not infringe privately owned rights. Reference herein to any specific commercial product, process, or service by its trade name, trademark, manufacturer, or otherwise, does not necessarily constitute or imply its endorsement, recommendation, or favoring by the US Government or any agency thereof, or the Regents of the University of California. The views and opinions of authors expressed herein do not necessarily state or reflect those of the US Government or any agency thereof or the Regents of the University of California.

\section{Compliance with ethical standards}

Competing interests The authors declare that they have no competing interest.

Open Access This article is licensed under a Creative Commons Attribution 4.0 International License, which permits use, sharing, adaptation, distribution and reproduction in any medium or format, as long as you give appropriate credit to the original author(s) and the source, provide a link to the Creative Commons licence, and indicate if changes were made. The images or other third party material in this article are included in the article's Creative Commons licence, unless indicated otherwise in a credit line to the material. If material is not included in the article's Creative Commons licence and your intended use is not permitted by statutory regulation or exceeds the permitted use, you will need to obtain permission directly from the copyright holder. To view a copy of this licence, visit http://creativecommons.org/licenses/by/4.0/.

\section{References}

Abbott G, Al E (2018) Hurricane Harvey. Impact and Response in Harris County, Harris County 
Allen M (2003) Liability for climate change. Nature 421:891-892

Bindoff N, Stott P, Achutarao M, Allen M, Gillett N, Gutzler D, Hansingo K, Hegerl G, Hu Y, Jain S, Mokhov I, Overland J, Perlwitz J, Sebbari R, Zhang X (2013) Detection and attribution of climate change: from global to regional. In: Stocker T, Qin D, Plattner G-K, Tignor M, Allen SK, Boschung J, Nauels A, Xia Y, Bex V, Pm M (eds) Climate Change 2013 The Physical Science Basis: Working Group I Contribution to the Fifth Assessment Report of the Intergovernmental Panel on Climate Change. Cambridge University Press, Cambridge

Burke M, Hsiang SM, Miguel E (2015) Global non-linear effect of temperature on economic production. Nature 527:235

Easterling DR, Kunkel KE, Wehner MF, Sun L (2016) Detection and attribution of climate extremes in the observed record. Weather Clim Extremes 11:17-27

Ebert-Uphoff I, Deng Y (2012) Causal discovery for climate research using graphical models. J Clim 25:56485665

Emanuel K (2017) Assessing the present and future probability of Hurricane Harvey's rainfall. Proc Natl Acad Sci 114:12681-12684

Frame DJ, Rosier SM, Noy I, Harrington LJ, Carey-Smith T, Dean S (2018) Estimating financial costs of climate change in New Zealand: an estimate of climate change-related weather event costs. The Treasury Living Standards Framework, The Treasury

Herring SC, Christidis N, Hoell A, Kossin JP, Iii CJS, Stott PA (2018) Explaining extreme events of 2016 from a climate perspective. Bull Am Meteorol Soc 99:S1-S157

Herring SC, Hoell A, Hoerling MP, Kossin JP, Iii CJS, Stott PA (2016) Explaining extreme events of 2015 from a climate perspective. Bull Am Meteorol Soc 97:S1-S145

Herring SC, Hoerling MP, Kossin JP, Peterson TC, Stott PA (2015) Explaining extreme events of 2014 from a climate perspective. Bull Am Meteorol Soc 96:S1-S172

Huizinga, J., DE Moel, H. \& Szewczyk, W. (2017). Global flood depth-damage functions: methodology and the database with guidelines. European Union

INFORMATION, N. C. F. E (2018). U.S. billion-dollar weather and climate disasters. NOAA

Jeon S, Paciorek CJ, Wehner MF (2016) Quantile-based bias correction and uncertainty quantification of extreme event attribution statements. Weather Clim Extremes 12:24-32

Jonkman SN, Godfroy M, Sebastian A, Kolen B (2018) Brief communication: loss of life due to hurricane Harvey. Nat Hazards Earth Syst Sci 18:1073-1078

Kalkuhl, M. Wenz, L. (2018). The impact of climate conditions on economic production. Evidence from a Global Panel of Regions. ZBW - Leibniz Information Centre for Economics

Kharin VV, Flato GM, Zhang X, Gillett NP, Zwiers F, Anderson KJ (2018) Risks from climate extremes change differently from $1.5^{\circ} \mathrm{C}$ to $2.0^{\circ} \mathrm{C}$ depending on rarity. Earth's Future 6:704-715

Lindner J. Fitzgerald S. (2018). Immediate report - final. Hurricane Harvey - storm and flood information. In: MEMORANDUM, H. C. F. C. D. (ed.)

Millar RJ, Fuglestvedt JS, Friedlingstein P, Rogelj J, Grubb MJ, Matthews HD, Skeie RB, Forster PM, Frame DJ, Allen MR (2018) Reply to 'interpretations of the Paris climate target'. Nat Geosci 11:222-222

Nordhaus WD (1993) Rolling the 'DICE': an optimal transition path for controlling greenhouse gases. Resour Energy Econ 15:27-50

Nordhaus WD (2010) The economics of hurricanes and implications of global warming. Clim Chang Econ 1:120

Nordhaus WD, Boyer J (1999) Roll the DICE again: economic models of global warming. MIT Press

Noy I (2016) A global comprehensive measure of the impact of natural hazards and disasters. Glob Pol 7:56-65

Noy I, Dupont W (2018) The long-term consequences of disasters: what do we know, and what we still Don't. Int Rev Environ Resour Econ 12:325-354

OFFICE OF AIR QUALITY PLANNING AND STANDARDS, U. S. E. P. A. 2017. Regulatory impact analysis for the review of the clean power plan: Proposal In: AGENCY, U. S. E. P. (ed.). U.S. Environmental Protection Agency, Office of Air Quality Planning and Standards, Research Triangle Park, North Carolina 27711

Oldenborgh GJV, Wiel KVD, Sebastian A, Singh R, Arrighi J, Otto F, Haustein K, Li S, Vecchi G, Cullen H (2017) Attribution of extreme rainfall from Hurricane Harvey, august 2017. Environ Res Lett 12:124009

Otto FEL, Massey N, Van Oldenborgh GJ, Jones RG, Allen MR (2012) Reconciling two approaches to attribution of the 2010 Russian heat wave. Geophys Res Lett 39:L04702

Patricola CM, Wehner MF (2018) Anthropogenic influences on major tropical cyclone events. Nature 563:339346

Pearl J (2009) Causality. Cambridge University Press, Cambridge

Peterson TC, Stoot PC, Stephanie H (2012) Explaining extreme events of 2011 from a climate perspective. Bull Am Meteorol Soc 93 
Peterson TC, Hoerling MP, Stott PA, Herring SC (2013) Explaining extreme events of 2012 from a climate perspective. Bull Am Meteorol Soc 94:S1-S74

Risser MD, Wehner MF (2017) Attributable human-induced changes in the likelihood and magnitude of the observed extreme precipitation during Hurricane Harvey. Geophys Res Lett 44:12,457-12,464

Smith AB, Katz RW (2013) US billion-dollar weather and climate disasters: data sources, trends, accuracy and biases. Nat Hazards 67:387-410

Trenberth KE, Cheng L, Jacobs P, Zhang Y, Fasullo J (2018) Hurricane Harvey links to ocean heat content and climate change adaptation. Earth's Future 6:730-744

UNFCCC.( 2018)Informal compilation proposal by the President. Katowice Climate Change Conference, 15 December 2018 Katowice UNFCCC

UNISDR (2015) Global assessment report on disaster risk reduction. United Nations Office for Disaster Risk Reduction, Geneva

Viscusi WK, Aldy JE (2003) The value of a statistical life: a critical review of market estimates throughout the world. J Risk Uncertain 27:5-76

Wang SYS, Lin Z, Jin-Ho Y, Phil K, Robert RG (2018) Quantitative attribution of climate effects on Hurricane Harvey's extreme rainfall in Texas. Environ Res Lett 13:054014

Weitzman ML (2012) GHG targets as insurance against catastrophic climate damages. J Public Econ Theory 14: 221-244

Wing OEJ, Sampson CC, Bates PD, Quinn N, Smith AM, Neal JC (2019) A flood inundation forecast of Hurricane Harvey using a continental-scale 2D hydrodynamic model. J Hydrol X 4:100039

Yonson R, Noy I, Gaillard J (2018) The measurement of disaster risk: an example from tropical cyclones in the Philippines. Rev Dev Econ 22:736-765

Publisher's note Springer Nature remains neutral with regard to jurisdictional claims in published maps and institutional affiliations. 